\title{
INFUENCE OF SELECTED PHARMACEUTICALS ON BIOGAS PRODUCTION IN MESOPHILIC ANAEROBIC FERMENTATION
}

\author{
Kristína ŠEFČOVIČOVÁ ${ }^{1}$, Igor BODÍK ${ }^{2}$, Veronika KVORKOVÁ ${ }^{1}$, \\ Juraj MICHÁLEK ${ }^{1}$, Andrey KORSHUNOV ${ }^{3}$, Maroš SOLDÁN ${ }^{1}$ \\ ${ }^{1}$ SLOVAK UNIVERSITY OF TECHNOLOGY IN BRATISLAVA \\ FACULTY OF MATERIALS SCIENCE AND TECHNOLOGY IN TRNAVA \\ INSTITUTE OF INTEGRATED SAFETY \\ Ulica JÁna Bottu 2781/25, 91724 TrNaVA, SlovaK Republic \\ e-mail: kristina.sefcovicova@ stuba.sk, veronika.kvorkova@stuba.sk, \\ juraj.michalek@stuba.sk,maros.soldan@ stuba.sk \\ ${ }^{2}$ SLOVAK UniVERSITY OF TECHNOLOGY IN BRATISLAVA \\ FACULTY OF CHEMICAL AND FOOD TECHNOLOGY \\ INSTITUT OF CHEMICAL AND ENVIRONMENTAL ENGINEERING \\ RADLINSKÉHO 9, 81237 BRATISLAVA, SLOVAK REPUBLIC \\ e-mail: igor.bodik@ stuba.sk \\ ${ }^{3}$ Federal State Budgetary Institution of SCIENCE „UdMur FEDERAL ReSEARCh CENTER \\ OF THE URAL BRANCH OF THE RUSSIAN ACADEMY OF SCIENCES“ \\ INSTITUTE OF MECHANICS \\ 426000, T. BARAMZINOY STR., 34, IZHEVSK, RUSSIA \\ e-mail: maguser_kai@mail.ru \\ Received 28 April 2021, Accepted 31 May 2021, Published 20 July 2021
}

\begin{abstract}
This article deals with pharmaceutical compounds as micropollutants in anaerobic digestion of sludge from waste water treatment plant (WWTP). Part of the work included the research into presence of pharmaceuticals in different types of waters. Description of anaerobic fermentation process is also important in terms of optimal conditions. The practical aim of the investigation was preparation of a model of anaerobic fermentation of sewage sludge, where influence of pharmaceuticals on mesophilic anaerobic digestion was monitored. Wash out of micropollutants from sludge in big semicontinuous anaerobic reactors was running since October 2013. The resulting non-adapted sludge from mesophilic reactor was used since March 2014 for pharmaceuticals tests in half-a-litre glass bottles with a septum cap. The compounds of interest were diclofenac, tramadol, ibuprofen, carbamazepine and amoxicillin and their concentration in the tested sludge was $10 \mu \mathrm{g} / \mathrm{L}$ and $500 \mu \mathrm{g} / \mathrm{L}$. The results showed that pharmaceuticals have different influence on the amount of produced biogas even if they are from the same therapeutic group. In the low concentration, the inhibition was present for diclofenac, carbamazepine and amoxicillin, at the high concentration, while diclofenac showed
\end{abstract}


almost no influence. Other compounds caused a stimulative effect on the process. The mixture of all pharmaceuticals of interest in low concentration was stimulative at first, while it was inhibotory since mid-time of the test.

\section{Keywords}

Pharmaceuticals, micropollutants, anaerobic fermentation, sewage sludge

\section{INTRODUCTION}

Studies into the presence of pharmaceuticals in the environment probably initiated the accidental discovery of clofibric acid as a metabolite of the fat regulator clofibrate in the aquatic ecosystems in Germany and Switzerland. However, clofibric acid and its metabolites were first detected in water samples from WWTPs in the USA in the 1970s. In Germany, it has already been found in drinking water, and, together with other polar pharmaceuticals such as carbamazepine, primidone and iodinated contrast media, in groundwater. Over the following years, more than 80 drugs and their metabolites were discovered in the aquatic ecosystems in Brazil, Canada, USA and in many countries of Europe. The above-mentioned compounds are found at the concentrations of several $\mu \mathrm{g} / \mathrm{L}$ in sewage and surface water below the WWTP [1]. Data on the inflow concentration of the WWTP give information on the consumption of pharmaceuticals in the given area; the concentrations in the effluent and in the sludge are important from an environmental point of view [2]. Drugs are metabolized to varying degrees in the human body, and their excreted metabolites and unchanged parent compounds may also undergo further modification due to the biological, chemical, and physical processes in wastewater treatment plants (WWTPs) as well as subsequent uptake by the human body through drinking water [3]. It is obvious that the concentrations of pharmaceuticals will be higher in hospital wastewater. For example, in X-ray contrast media, it was up to 70 times higher [4]. However, WWTPs are not designed to effectively remove these micropollutants, and many of them are easily adsorbed to the sludge, so that the elimination of drugs at activated sludge WWTPs is incomplete. As a result, drugs enter the environment through treated effluents and the application of stabilised sludge as biomass to soils [5], and then return to the human body through drinking water, food chain and the reuse of treated wastewater for domestic purposes. Moreover, the increasing presence of pharmaceutical compounds in the environment can have various effects on living organisms, including chronic toxicity, endocrine disruption, toxic effects on reproduction and antibiotic resistance of microorganisms, thus reducing the therapeutic potential against the human and animal pathogens [5]. For our experiment, we chose the following drugs: ibuprofen (IBP), diclofenac (DCF), carbamazepine (CARB) and also tramadol (TRM) and amoxicillin (AMOX).

\section{MATERIALS AND METHODOLOGY OF EXPERIMENT}

\section{Batch anaerobic reactors - methanogenic tests}

Methanogenic tests were performed for five different drugs at $10 \mu \mathrm{g} / \mathrm{L}$ (marked by number 1) and $500 \mu \mathrm{g} / \mathrm{L}$ (marked by number 2) and their mixture, in which each drug had a concentration of $10 \mu \mathrm{g} / \mathrm{L}$. Chemical structure of the selected drugs is shown in Figure 1. From pure drugs, stock solutions at a concentration of $1 \mathrm{~g} / \mathrm{L}$ were prepared, from which working solutions at a concentration of $4 \mathrm{mg} / \mathrm{L}$ or $10 \mathrm{mg} / \mathrm{L}$ were prepared for dosing into glass bottles. In the test with diclofenac at a low concentration, $20 \mathrm{ml}$ of substrate was dosed, in other tests it was $15 \mathrm{ml}$ each, except for tramadol at a high concentration, when it was dosed at $14 \mathrm{ml}$. The substrate was a solution of $10 \mathrm{ml}$ of g-phase, $10 \mathrm{ml}$ of urea $(200 \mathrm{mg} / \mathrm{L})$ made up to $200 \mathrm{ml}$ with aqueous water. Monitoring the inhibition of biogas production of selected drugs was performed 
according to the dissertation thesis of Šmejkalová (1998) by a series of methanogenic tests for each drug and its tested concentration - each series included a blank sludge experiment without substrate - endogenous biogas production (SL), three parallel experiments with sludge and substrate (KS) and 3 parallel experiments with sludge, substrate and drug at the selected concentration (KSL). Glass bottles with a septum cap with a volume of $0.5 \mathrm{~L}$ were used as batch anaerobic reactors for methanogenic tests, which were filled with mesophilic sludge to a working volume of $0.33 \mathrm{~L}$ (recommended ratio of suspension volume to gas space volume should be 2:1), diluted to an organic dry matter concentration of $1 \mathrm{~g} / \mathrm{L}$.

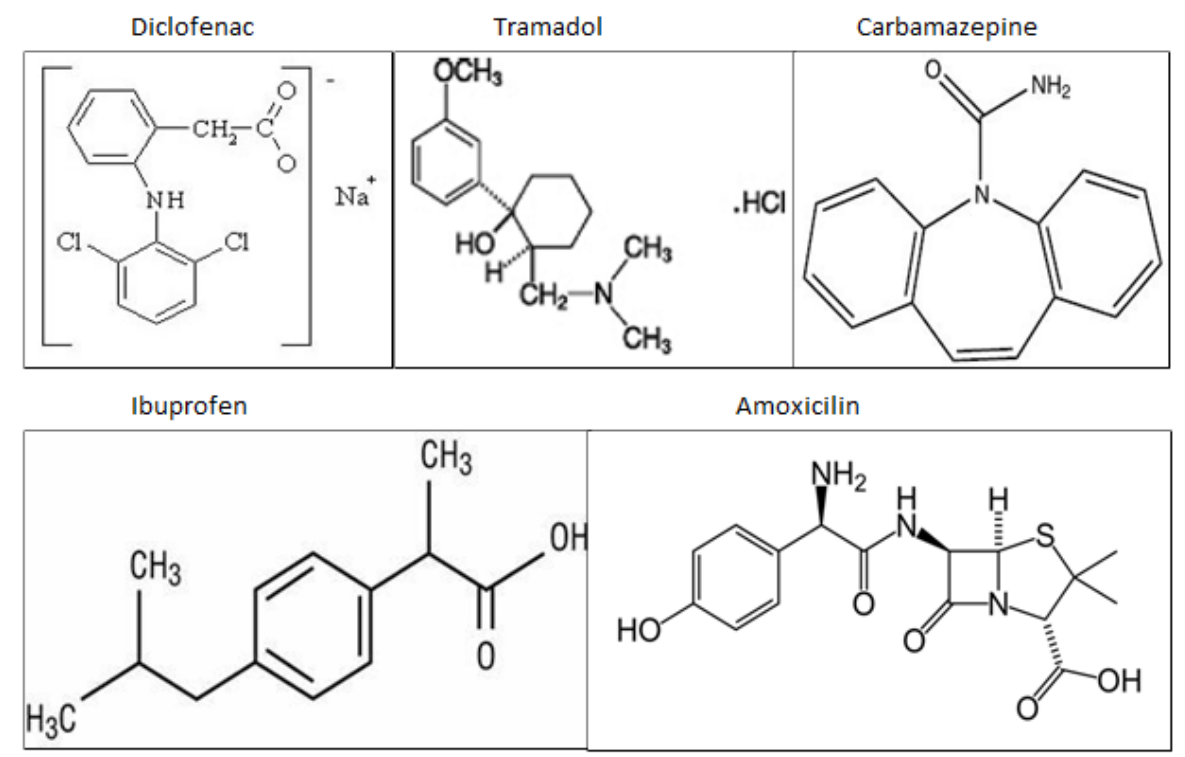

Figure 1 Chemical structure of selected pharmaceuticals

Biogas production was monitored using the volume measurement method by determining the volume of liquid ( $2 \mathrm{~mol} / \mathrm{L} \mathrm{NaOH}$ solution) in a burette displaced by biogas by inserting a needle connected to the burette. The gas accumulated in the gas space of the bottle is released at certain intervals (once a day, later once every two days).

\section{Determination of drug influence}

The effect of each drug on anaerobic fermentation was evaluated at first by graphs of cumulative biogas production for individual parallel samples and their averages as a function of time. From the graph of average biogas productions related to the amount of sludge used $\mathrm{V}=0.33 \mathrm{~L}$, the maximum specific methanogenic activity $Q_{s p e c}$ was always determined according to equation (1):

$$
Q_{\text {spec }}=\frac{k}{C L_{550}},
$$

where $k\left[\mathrm{ml} \mathrm{L}^{-1} \mathrm{~h}^{-1}\right]$ is the guideline at the beginning of the test, when biogas production is the highest, and $\mathrm{CL}_{550}[\mathrm{~g} / \mathrm{L}]$ is the amount of total organic matter.

Next, the inhibition rate was " $I$ " expressed by equation (2) according to Gartiser et al. (2007), which is also shown graphically as a function of time:

$$
I=\left(1-\frac{V_{t}}{V_{c}}\right) \mathrm{x} 100,
$$


where $V_{t}$ is the volume of biogas from the test drug bottle and $V_{c}$ is the volume of biogas from the drug-free control bottle, the average values of parallel samples.

The effect of drugs was also assessed simply by comparing the decrease in COD in the sample with substrate (KS), and in the sample with substrate and drug (KSL) as the COD removal efficiency according to equation (3):

$$
\eta_{\mathrm{CHSK}}=\frac{\mathrm{COD}_{\text {start }}-\mathrm{COD}_{\mathrm{end}}}{\mathrm{COD}_{\text {start }}}
$$

\section{Observation of process in septum bottles}

One parallel experiment of the second and third series was always used for sampling for $\mathrm{pH}$ analysis, total organic matter $\mathrm{CL}_{550}$ and COD at the beginning and the end of the test. $\mathrm{PH}$ values were measured by a Hanna $\mathrm{pH}$ meter, and later by a portable $\mathrm{HI} 9124 \mathrm{pH}$ meter. The COD value was determined in a sample filtered through a membrane filter with a pore size of $1.5 \mu \mathrm{m}$ spectrophotometrically by LCK 514 cuvette tests $(100$ - $2000 \mathrm{mg} / \mathrm{L})$ from Hach-Lange. Concentration of the total substances was determined gravimetrically according to Horáková (2007).

\section{Research}

The main route of entry of pharmaceutical compounds into wastewater is their excretion by the human body in an unchanged or metabolized form, but also an inappropriate way of disposing of the unused or expired pharmaceuticals through toilets, septic tanks or directly into sewers [1]. Pharmaceuticals in raw wastewater are generally in the range of $10^{-3}$ to $10^{-6} \mathrm{mg} / \mathrm{L}$ [3].

Concentration ratios of micropollutants are strongly influenced by weather, especially precipitation, which has a diluting effect on wastewater, and conversely, dry weather increases the concentrations of compounds. Pharmaceuticals concentration level is conditioned by the rate of excretion and the degree of metabolism. For some compounds, the low excretion rate (ibuprofen, carbamazepine, sulfamethoxazole and diclofenac) is offset by high consumption and is thus found in relatively high concentrations in wastewater [4].

The highest inflow values were found for NSAIDs (non-steroidal anti-inflammatory drugs), as expected due to their high consumption [2]. Moreover, the most frequently detected class of pharmaceuticals in the environment is that of NSAIDs and analgetics [9], of which diclofenac and ibuprofen were most commonly found in environmental samples of surface waters, groundwater and/or tap or drinking waters [10].

Sewage sludge can contain many xenobiotics of organic nature, including pharmaceuticals with potential to be taken up by plants and animals, thus accumulating in the food chain, as well as leaching into groundwater [11]. Thus, biodegradable micropollutants that have been adsorbed on the primary and excess activated sludge can potentially decompose in digestion tanks during the stabilization of the raw sludge. One of the studies reporting the presence of pharmaceuticals in raw sludge was conducted in France by Bourdat-Deschamps et al. (2017), who found in the matric concentration of diclofenac $1 \mathrm{ng} / \mathrm{g}$, ibuprofen $0.11 \mathrm{ng} / \mathrm{g}$ and carbamazepine $0.036 \mathrm{ng} / \mathrm{g}$ [12]. After anaerobic stabilization, the concentration values of most of those compounds in the sludge decreased [13].

Pharmaceuticals are designed to interfere with the function of biological elements in the human body, so they are expected to have some effect on the normal function of bacterial cells involved in anaerobic stabilization. Methanogens have been found to be sensitive to only certain antibiotics [7]. 


\section{RESULTS}

Comparison of average COD removal efficiencies is provided in Figure 2, where the mean $\mathrm{KS}$ is the average value of COD removal efficiencies in all drug-free samples. It can be seen from the graph that diclofenac should have the most inhibitory effect at a low concentration, which allowed the removal of the substrate only slightly over $20 \%$. According to Fountalakis et al. (2008), diclofenac was resistant to anaerobic biodegradation, and its concentration was constant during the experiments. In their experiment, diclofenac caused a moderate inhibition of the anaerobic process with rapid increase, while increasing drug concentration. Diclofenac is described as highly bactericidal for both gram-positive and gramnegative bacteria, suppressing the synthesis of their DNA, and thus acting on specific bacteria. In addition, its effect specifically on anaerobic archaea, which contain a DNA precursor, is not direct to the biological membrane, as in the case of surfactants. As seen in Figure 3, diclofenac at low concentration, though it does not have the lowest biogas production after 1 day, after 7 days even after 16 days, and it slightly stimulated biogas production also at higher concentration.

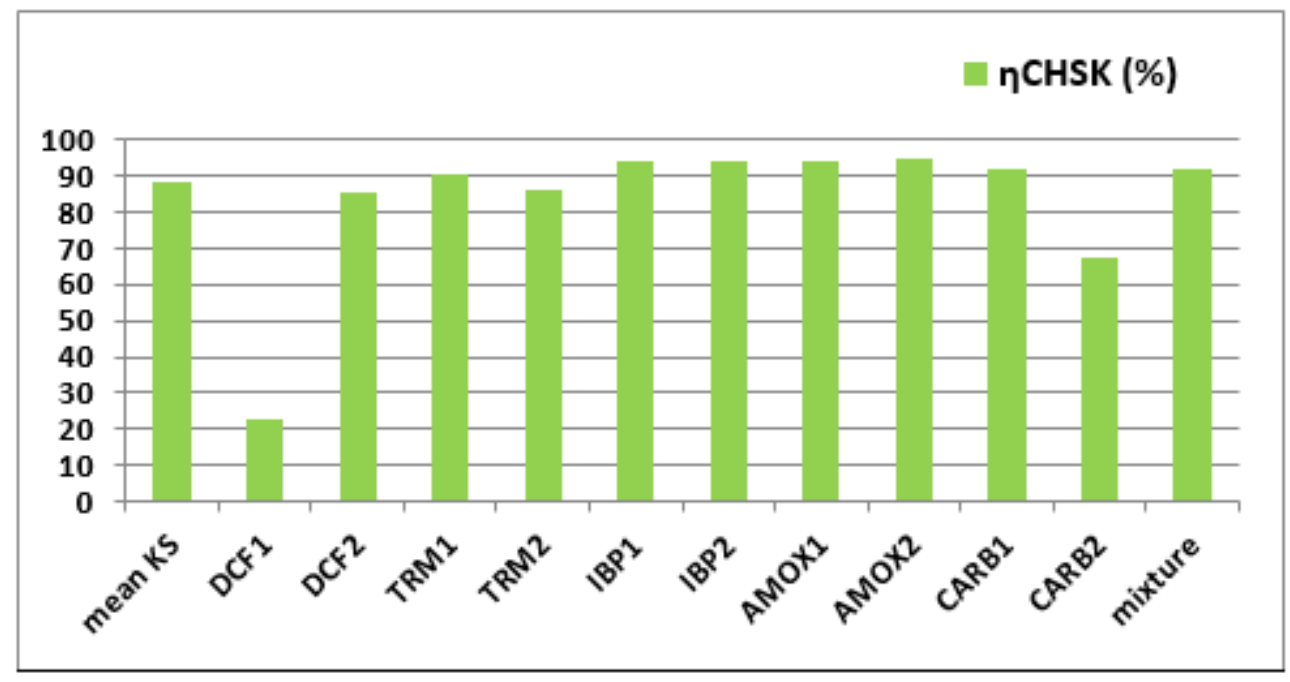

Figure 2 Comparison of COD removal efficiency for individual investigational drugs and their concentrations

So, based on Figure 3, we can assess whether the value of COD removal efficiency means inhibition of biogas production. For comparison, according to Carballa et al. (2007), diclofenac caused severe inhibition at high concentration. 


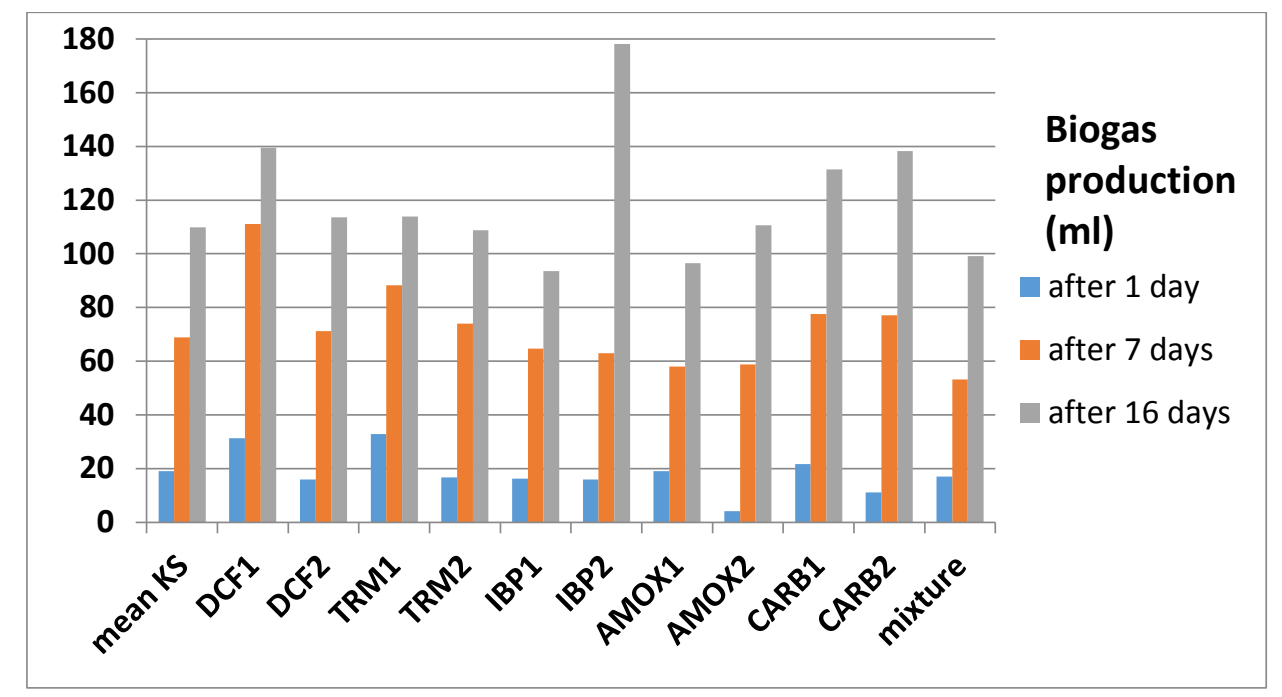

Figure 3 Comparison of total biogas production at certain times for individual tests

Comparison of the drug effect on biogas production through the degree of inhibition is provided in Figure 4, which compares the minimum and maximum inhibition, and Figure 5, which shows the average inhibition. It can be seen there that high-concentrated diclofenac, lowconcentrated carbamazepine, ibuprofen and amoxicillin at both concentrations and the drug mixture show both inhibitory and stimulatory effects, with the fact that diclofenac and amoxicillin at $500 \mu \mathrm{g} / \mathrm{L}$ and the mixture are approximately equally positive and negative. Ibuprofen causes only a slight positive inhibition and distinctive stimulation; yet, at its high concentration, the stimulation is more distinct. According to Figure 3, high-concentrated ibuprofen have a stimulatory effect sometime after seven days, whereas diclofenac, for example, being stimulating from the beginning of the experiment.

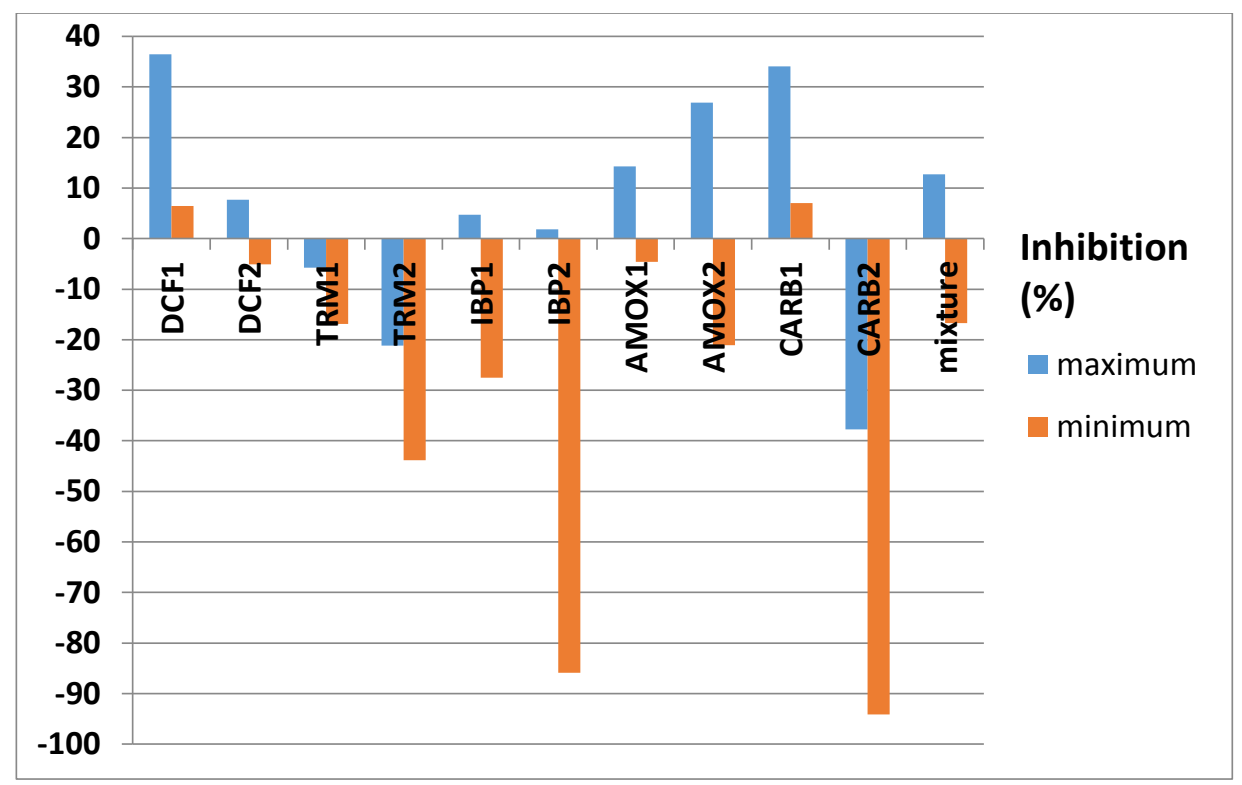

Figure 4 Comparison of minimum and maximum inhibition rates among drugs

Based on Figure 5, drugs cause positive inhibition of biogas production more often at rather low than at high concentration, at high concentration, they stimulate the process (diclofenac, 
carbamazepine, amoxicillin). For other pharmaceuticals with increasing drug concentration, the stimulation of biogas production increases (tramadol, ibuprofen). The antibiotic did not cause complete inhibition of the anaerobic fermentation process as we expected and as confirmed by literature. For example, Gartiser et al. (2007) found that none of the antibiotics they studied, including amoxicillin, completely inhibited biogas production. In our experiments, it was stimulating even at high concentration.

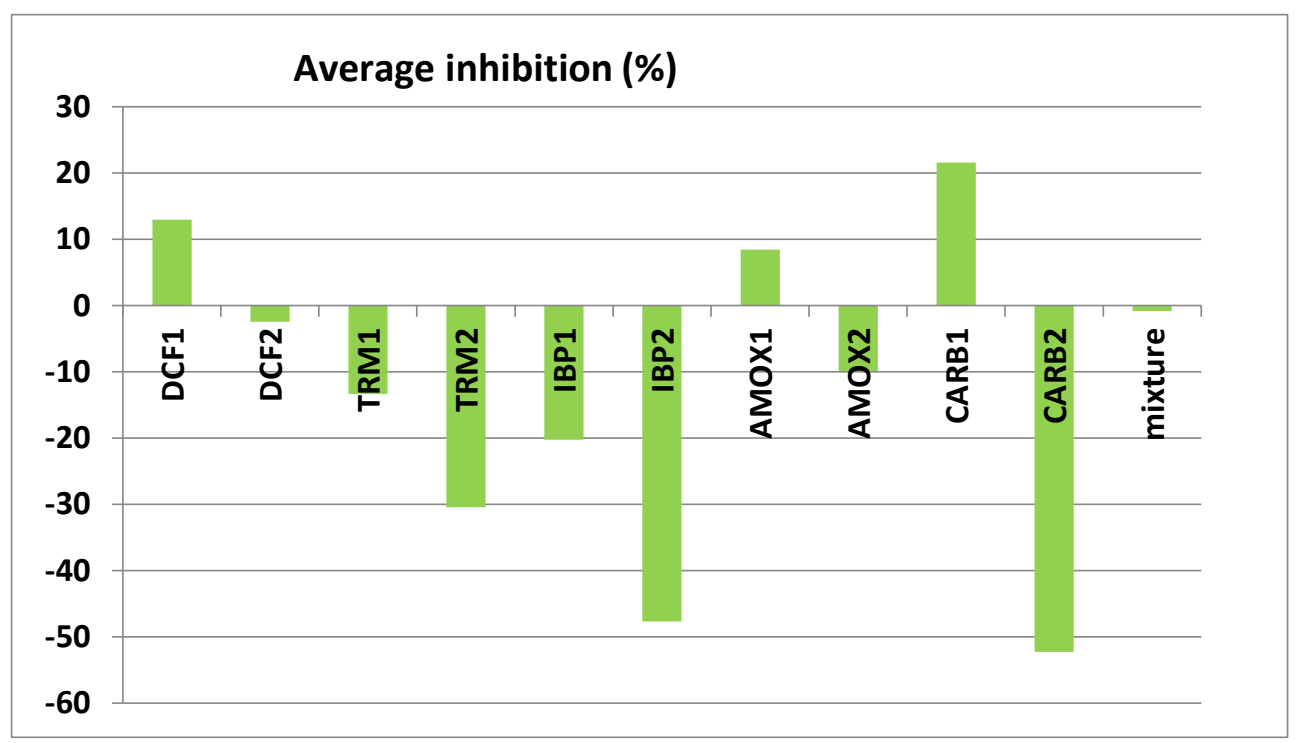

Figure 5 The mean inhibition due to individual drugs

As can be seen in Table 1, according to the maximum specific methanogenic activity, $\left(Q_{\text {spec }}\right)$, diclofenac, tramadol and carbamazepine would be stimulating at low concentration, while carbamazepine at high concentration. When evaluating the effect of drugs on biogas production through the $Q_{s p e c}$, it should be noted that this parameter corresponds to the state of the process only at the beginning of the test, and inhibition may occur at a time that is no longer evaluated by this parameter.

Table 1 Maximum specific methanogenic activity for every drug, its mixture and average value of samples without drugs

\begin{tabular}{|l|c|c|c|c|c|c|c|c|c|c|c|c|}
\hline & $\begin{array}{c}\text { mean } \\
\text { KS }\end{array}$ & DCF1 & DCF2 & TRM1 & TRM2 & IBP1 & IBP2 & AMOX1 & AMOX2 & CARB1 & CARB2 & MIXTURE \\
\hline $\boldsymbol{Q}_{\text {spec }}(\mathbf{m l} / \mathbf{g} / \mathbf{h})$ & 1.81 & 3.34 & 0.76 & 3.46 & 1.34 & 0.79 & 1.45 & 1.38 & 0.96 & 1.80 & 1.86 & 1.56 \\
\hline
\end{tabular}

Thus, the maximum specific methanogenic activity corresponds to the effect of drugs at the beginning of the test. If $Q_{\text {spec }}$ is higher in the sample without drug (KS) and the effect of this drug is positive or, conversely, $Q_{s p e c}$ is higher in the sample with drug and its effect is negative, the maximum specific methanogenic activity is a suitable parameter to describe the effect.

\section{DISCUSSION}

The corresponding parallel samples did not always correspond to each other sufficiently, which can be attributed to the imperfect mixing and distribution of the storage, differences between the individual bottles, or even different degrees of adaptation to the same conditions. However, statistics are also applied to biological systems, so it would be desirable to build several parallel samples (at least 10) in one test, from which it would be possible to create an 
adequate average, or even exclude the samples that significantly deviate from the majority trend.

In all tests, the $\mathrm{pH}$ decreased from slightly basic to the values in the range of $6.5-7.0$, optimal for methane production. However, the difference between the drug and non-drug samples may not be indicative of the acidic nature of the drug, as this difference was also in drug tests that are not significantly acidic in structure (tramadol, ibuprofen and amoxicillin are acidic in structure). Also, in the case of positive inhibition, the $\mathrm{pH}$ in the drug-free sample was not always lower than in the drug-free sample as a result of NMK accumulation. Therefore, we did not consider it necessary to measure the concentration of NMK as an indicator of inhibition of biogas production. In addition, high biogas production may be mainly in the production of $\mathrm{CO}_{2}$ with a low proportion of the desired energy-rich $\mathrm{CH}_{4}$ - thus the inhibitory effect was not reflected in reduced biogas production of tramadol, ibuprofen, or diclofenac and carbamazepine at high concentration. Therefore, it would be appropriate in the future to perform tests in larger volumes, which would allow the production of a larger amount of biogas, which is needed for the biogas composition analyzer.

The inhibitory effect was directly correlated with the affinity of pharmaceuticals for sorption on anaerobic sludge [14]. According to Carballa (2007), the more hydrophobic the compound, the worse its effect on methane production (propanolol hydrochloride, diclofenac sodium and ofloxacin). Increasing concentrations of neomycin and hydromycin B initially causes a constant increase in inhibition, but at higher concentrations, the inhibitory effect weakened. Diclofenac caused severe inhibition at high concentrations, carbamazepine and sulfomethoxazole, did not affect methanogenesis even at high concentrations [11]. Studies show that the effect of pharmaceuticals on anaerobic fermentation is short-lived and appears to be negligible under normal conditions when pharmaceuticals are identified at ng/L concentrations. Thus, no inhibitory effect of pharmaceuticals at the usual concentrations found at WWTPs is expected [15].

\section{CONCLUSION}

There are many ways how to describe influence of drugs on anaerobic digestion. Based on our results, next task should be to find the best parameter for the inhibition determination. Furthermore, beside pharmaceuticals impact monitoring, the degradation monitoring is still more important with determination of impact on living organism. However, the biggest challenge remains finding the process able to remove the most of presence of micropollutants at the lowest cost. This process should be also environmentally friendly, producing as little additional waste as possible. Moreover, the public should be better informed about the unnecessary and excessive use and inappropriate disposal of medical preparations.

\section{Acknowledgement}

This research was funded by the APVV project 122/12.

\section{References}

[1] HEBERER, T. 2002. Occurrence, fate, and removal of pharmaceuticals residues in the aquatic environment: a review of recent research data. Toxicology letters, 131(1-2), 5-17. ISSN0378-4274.

[2] JELIC, A., GROS, M., GINEBREDA, A., CESPEDES-SÁNCHEZ, R., VENTURA, F., PETROVIC, M., BARCELO, D. 2011. Occurrence, partition and removal of pharmaceuticals in sewage water and sludge during wastewater treatment. Water Research, 45(3), 1165-1176. ISSN 0043-1354. 
[3] VERLICCHI, P., AL AUKIDY, M., ZAMBELLO,E. 2012. Occurrence of pharmaceutical compounds in urban wastewater: Removal, mass load and environmental risk after a secondary treatment-A review. Science of the Total Environment, 429, 123-155. ISSN 0048-9697.

[4] LUO, Y., GUO, W., NGO, H.H.,NGHIEM, L.D., HAI,F.I., ZHANG J., LIANG, S., WANG, X.C. 2013. A review on the occurrence of micropollutants in the aquatic environment and their fate and removal during wastewater treatment. Science of the Total Environment, 473-474, 619-641. ISSN 0048-9697.

[5] GAO, P., DING, Y., LI, H., XAGORARAKI, I. 2012. Occurrence of pharmaceuticals in a municipal wastewater treatment plant: Mass balance and removal processes. Chemosphere, $\mathbf{8 8}(1)$, 17-24. ISSN 0045-6535.

[6] ŠMEJKALOVÁ, P. 1998. Tests of anaerobic biology degradation of organic matter. VŠCHT Prague. Dissertation thesis.

[7] GARTISER, S., URICH, E., ALEXY, R., KÜMMERER, K. 2007. Anaerobic inhibition and biodegradation of antibiotics in ISO test schemes. Chemosphere,66(10), 1839-1848.ISSN 00456535.

[8] HORÁKOVÁ, M. 2007. Water Analytics. 2nd ed. University of Chemical Technology, Prague 2007. 135 p. ISBN: 978-80-7080-520-6.

[9] FEKADU, S., ALEMAYEHU, E., DEWIL, R., VAN DER BRUGGEN, B. 2019. Pharmaceuticals in freshwater aquatic environments: a comparison of the African and European challenge. Science of The Total Environment, 654, 324-337. ISSN 0048-9697.

[10] AUS DER BEEK, T., WEBER, F.A., BERGMANN, A., HICKAMNN, S., EBERT, I., HEIN, A., KÜSTER, A. 2016. Pharmaceuticals in the environment-global occurrences and perspectives. Environmental Toxicology and Chemistry, 35(4), 823-835. doi:10.1002/etc.3339.

[11] CARBALLA, M., OMIL, F., TERNES, T., LEMA, J.M. 2007. Fate of pharmaceutical and personal care products (PPCPs) during anaerobic digestion of sewage sludge. Water Research, 41(10), 21392150. ISSN 0043-1354.

[12] BOURDAT-DESCHAMPS, M., FERHI, S., BERNET, N., FEDER, F., CROUZET, O., PATUREAU, D., MONTENACH, D., MOUSSARD, G.D., MERCIER, V., BENOIT, P., HOUOT, S. 2017. Fate and impacts of pharmaceuticals and personal care products after repeated applications of organic waste products in long-term field experiments. Science of the Total Environment, 607608, 271-280. ISSN 0048-9697.

[13] MARTÍN, J., CAMACHO-MUÑOZ, D., SANTOS, J.L., APARICIO, I., ALONSO,E. 2012. Occurrence of pharmaceutical compounds in wastewater and sludge from wastewater treatment plants: Removal and ecotoxicological impact of wastewater discharges and sludge disposal. Journal of Hazardous Materials, 239-240, 40-47.ISSN 0304-3894.

[14] STASINAKIS, A.S. 2012. Review on the fate of emerging contaminants during sludge anaerobic digestion. Bioresource Technology, 121, 432-440. ISSN 0960-8524.

[15] FOUNTOULAKIS, M.S., STAMATELATOU, K., LYBERATOS,G. 2008. The effect of pharmaceuticals on the kinetics of methanogenesis and acetogenesis. Bioresource Technology, 99(15), 7083-7090. ISSN 0960-8524.

\section{ORCID}

Maroš Soldán 0000-0003-1520-1051 